\title{
Indication of Urban expansion of Gujranwala city (Pakistan) by Remote sensing and GIS
}

\author{
Asad Aziz*, Muhammad Mushahid Anwar, Mehwish Rani, Shawaz Ahmad, Saqib Zaheer \\ Department of Geography, University of Gujrat, Gujrat., Village Rehsian.P/O Kotla Arab Ali khan \\ Tehsil Kharian Distt Gujrat., 50990 Kotla arab ali khan, Pakistan
}

Received: 22 November 2017

Accepted: 14 April 2018

Published online: 30 December 2019

\begin{abstract}
Land-cover by land-use shows the influence of human on earth surface by different phenomena's, ecological processes and human activities, its indication is a parameter of measurement how and with which extent the human influenced the natural surface with temporal variations. The change detection technique is used based upon the temporal observations from 2000 to 2015. Study area is one of the most populated city of Pakistan where industrial revolution is at its peak. The whole study area is categorized into four classes (i.e. Agricultural, Barren, Built-up and semi natural surfaces). The observational intervals were divided into three main classes i.e. 2000 to 2005, 2005 to 2010 and 2010 to 2015. Remarkable changes were occurred in built up area from 2000 to 2015 which is 38.6 $\%$ of total area, while the total change/decreased in barren land is -3329 (ha), similarly the Parks and grasses are also in decreasing extent and affect the local biodiversity and natural environment. The land cover is directly proportional to population expansion of urban city. For making the prediction of future urban expansion, previously occurred changes were aggregated to come up with a single value and then adding it to the recent land-use values. The mapping and analysis was undertaken through techniques of remote sensing and GIS, which proved to be very effective to measure the changes, and trend of changes with time, this mapping not only tells us the scale of change but, also tells us the patterns and the forces which causes these changes.
\end{abstract}

Keywords: remote sensing, GIS, urban sprawl, ecology, time

\section{Introduction}

The identification of changing in land cover and urban sprawl by using GIS and Remote sensing techniques with time sequence is important aspect for management and better understanding the physical environment around the human. "Sprawl" may use to aware the disorder expansion of unstable development (Fichera et al. 2012). "Sprawl is term refers to collection of decision from individuals increasing the population and socio economic condition (Wilson et al. 2003). Land cover means the physical characteristics of the earth surface and Land use means the economic and social activities occurred at that land (Haines-Young 2009). This technique is an emerging technique among different

* Corresponding author: Asad Aziz

e-mail: asadazizpakistan@gmail.com 
fields of modern, disaster and social sciences, to identify the changing occurred in anything under examination. The land-use/land-cover has changed a lot by different human activities like increase of population, industrialization construction activities etc., and changed local environment. Land cover changing from a natural land surface into urban area is morphological conversion from structural point of view (Antrop 2000, 2004). To analyses the land-use changes in recent years, remote sensing techniques used to establish digital cartographic models, related to land-uses (i.e. grasses, crops land, built-up area and barren lands) to classified the changing with temporal aspect in urban region Gujranwala which gives indication about the Land Degradation Land usage and population growth. To monitor the changing occurred with time Remote sensing images are used from 2000 to 2015.In fact during 2000 to 2015 data shows a noticeable change by showing that the city is expanded from inner to out ward. Population grows towards outside the city shaped the urban expansion to the area (Angel et al. 2005). GIS and remote sensing is modern and helpful analytical tools to identify the spatial and temporal changing day to day throughout the world which were used in this research." Land is a base on which all human activities occurred and this base provide material necessary for the human life Land use and land change problem is a major problem in most of metropolises area in the world where a natural land surface is replaced by commercial lands" (Bolarinwa. 2009). Land change and Land use is related to socio-economic condition, urban development, increased of population and technical advancement in urbanism areas (Ali S.A and Tesgaya 2010). Land change and Land use are inter related to each other and changed into each other by various physical factors such as increase of Population (Ali S.A and Tesgaya. 2010). Land usage data base also gives us a lot of information about the population growth of local people, decision making for popper management system, administration and sequence of development (Bolarinwa 2009). Land usage in urbanization is loss of natural, open space and agricultural lands (Bolarinwa 2009). Land changed by two process natural or human activities. Thus land use data having different magnitude of expansion in different time session, in which grasses, agricultural area and crops are decreased. Urban sprawl is a main area of activities in worldwide problem which change the present environment (Ali S.A and Tesgaya 2010). Urban expansion is active in character, different factor making impact on rate of shift, the distribution and kind of urban expansion increasing in population is shaping express shift in area which effect the distribution and kind of urban expansion, (Solomon 1994; Ali S.A and Tesgaya 2010).The modern and technical instruments such as remote sensing and GIS are very effective driving and powerful tools to evaluate the changing in Land cover and land change. In past 300 years the change in natural environment like Land use for urbanization threaten the natural environment, which is mainly done in forms of desertification to clear the land for residency (Bolarinwa 2009). The earth surface is continuously changed with the passage of time and has a profound effect on natural environment ((Zubair and Opeyemi 2006) thus a visible and clear effect can be detected by Satellite imaginary data. Land usage and land cover change detection is very important component for batter planning and selection of areas for boundary selection to apply the laws for the welfare of the peoples (Zubair and Opeyemi 2006). Satellite base images are useful tools and provide us technical assistance to measure the man's influence on the earth surface with time. (Zubair and Opeyemi 2006). Transformation of land into built area also effect the local physical environment of that area, likes grasses decreased, agricultural land becomes destroyed and nature becomes deplete. For characterizing land "the land change science" is necessary to meet the challenging regarding land usage (Turner et al. 2007). Land is used by economic, social and political activities by human's (Manonmani and Suganya 2010). GIS and remotesensing data provide us a fundamental tool to examine the urban environment (Manonmani and Suganya 2010). The combined result of GIS and remote sensing data is fastest and easier to handle to study the urbanenvironment then the traditionalmethods such as surveying (Manonmani and Suganya 2010). The detection of urban expansion helps us for urban planning, decision making for urban management. The surface Aledo and 
evaporation changed the local climate by increasing the heat from anthropogenic activities and aerosols material which also changed the local ecology of the people. (Seto et al. 2011).

\section{Objectives}

- To find Land-use or land-cover changes by temporal variations.

- Detection of urban area expansion.

- Impacts of urban expansion on ecology.

- Future Predication for 2015 to 2030.

\section{Study Area}

The industrial city located in Punjab, Pakistan $32^{\circ} 9 \mathrm{~N} 74^{\circ} 11^{\prime}$ E.The seventh most populous city of Pakistani metropolitan areas. The important region of Punjab province located beside the main road that's linked the city with provisional capital Lahore, away from $80 \mathrm{~km}$. The local climate is hot semiarid (Bsh) according to Köppen System classification. Cool winter with average temperature $7^{\circ} \mathrm{C}$ and hot summer with temperature more than $42 \mathrm{C}^{0}$. The total area of this city is $3,198 \mathrm{~km}^{2}$ with population of 2,723,009according to UNDATA. After 2000 to onward this city expended very fast due to industrialization, urbanization and developments showing a remarkable change with time scale. Gujranwala city is 226 meters above from the sea level. Gujranwala share it border with Gujrat and several towns and villages. It has a vital road channels that linked the city with other important regions of Punjab like Faisalabad, Lahore, Gujrat etc. To avail the facilities and quality of life people moved and migrated toward urban city. It contains 97 local administrative units (Union Councils). The center of the Gujranwala consists of major urban area (2 union councils). It has annual average growth rate of 2.85\% (1981-1998)(Statistics 1999)

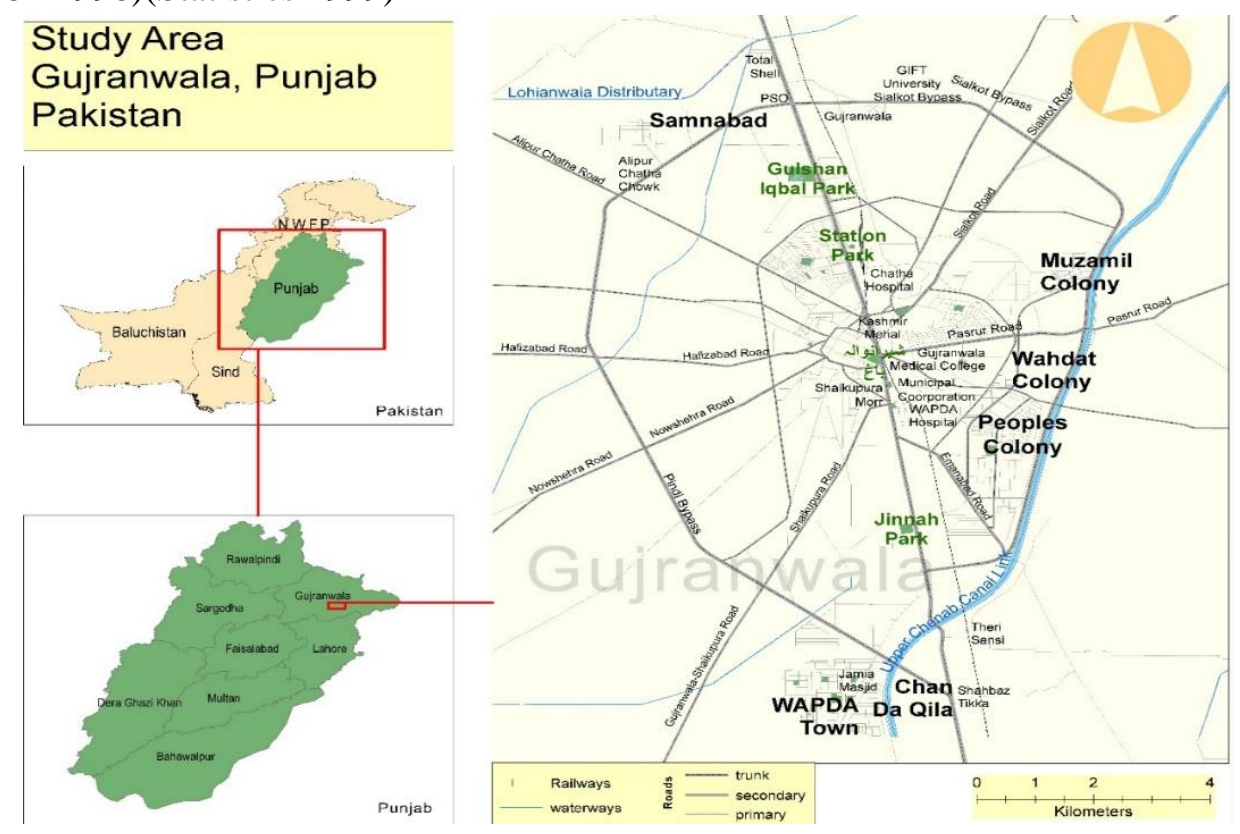

Fig. 3. Study area: Gujranwala, Punjab, Pakistan.

The whole urban city is divided into different colonies such as Satellite Town, Muzamil Colony, Samna bad, Peoples colony, Chan da Qila and Wapda Town. The main city is expending day to day outward due to increase of population. More and more towns are taking place each day. Developers are investing a lot. Most of these towns are developed on the fringes of the city in open areas or in Metropolitan areas where urban population is mixed with rural population. These metropolitan areas 
A. Aziz et al.

have much greater potential for development than that of cities. Our study area includes the main city and its round boundary to observe the spatial variation in Urbanization.

\section{Methodology}

Land-use or land-cover types were first selected which are to be measured. Images from Landsat 7 and Landsat 8 were selected. 2005 Landsat 7 image had slc off product which means it had black lines in it. To deal with that problem, previous Landsat 7 image (with slc on) was used to fill those dark lines. Images were imported in ENVI software. Field surveys were done in order to collect samples. Samples were points which had flowing attributes; location, type of land (urban, vegetation, barren, parks or grasses)

Classes (Tab. 1) were made and carried out for other images as well.

Tab. 1. Land-use and Land-cover types.

\begin{tabular}{|l|l|l|}
\hline$\#$ & Land-cover type & \multicolumn{1}{c|}{ Description } \\
\hline 1 & Barren Land & Empty area that is soon to be used for other land-use types \\
\hline 2 & Built-up Area & Artificially built-up land \\
\hline 3 & Parks and Grasses & Green spaces providing ecological services \\
\hline 4 & Vegetation Land & Area used to grow crops \\
\hline
\end{tabular}

For better results in image classification, different Landsat band combination were tried. However, the most effective seem to be the 321 (RGB) color bands for this study.

More than one polygons (objects) were selected from each image to improve the accuracy. Once all images were classified into land-cover categories, the vector files were exported, and imported in ESRI ArcMap. Where manual digitizing was done based on field surveys and cross checking. Some errors were still to be expected due to low resolution of Landsat images.

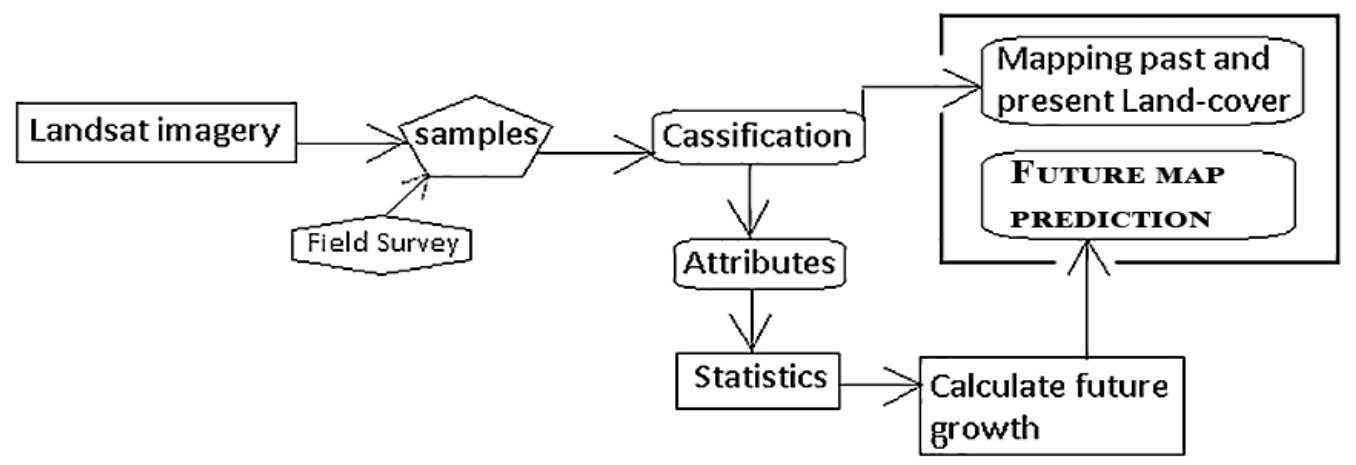

Fig. 4. Flowchart of Methodology.

ArcMap was used to calculate the area and percentages of each category. Tables were made and exported in Microsoft Excel where they were used to calculate the change and change per year using simple mathematical formulas.

$$
\begin{aligned}
& \text { Change in Landuse }=\text { Recent landuse area }- \text { Past Landuse area } \\
& \text { Change per year }=\frac{\text { Recent Landuse area }- \text { Past landuse area }}{\text { Interval }}
\end{aligned}
$$

For making the prediction of urban area in 2030, simple formula was used. Calculation were based on pixel quantity. The formula calculates the average change that occurs in every five years by 
A. Aziz et al.

adding the values of "change" and dividing it to the total number of values (3). The limitation of this formula was that, it can only calculate one land-use type at a time. In this study, only urban land-use type is analyzed for making a general prediction of urban expansion.

expected increase in next 5 years $=\frac{\text { change from } 2000 \text { to } 2005+\text { change from } 2005 \text { to } 2010+\text { change from } 2010 \text { to } 2015}{3}$

The resulting value is the average change that occurs in every five years. This value can be added in to the 2015 urban land-cover to come up with a prediction of 2020 urban expansion. To find out the urban land-use of year 2030, the average change value is multiplied by 3 .

\section{Results}

\section{Comparison of 2000 to 2005}

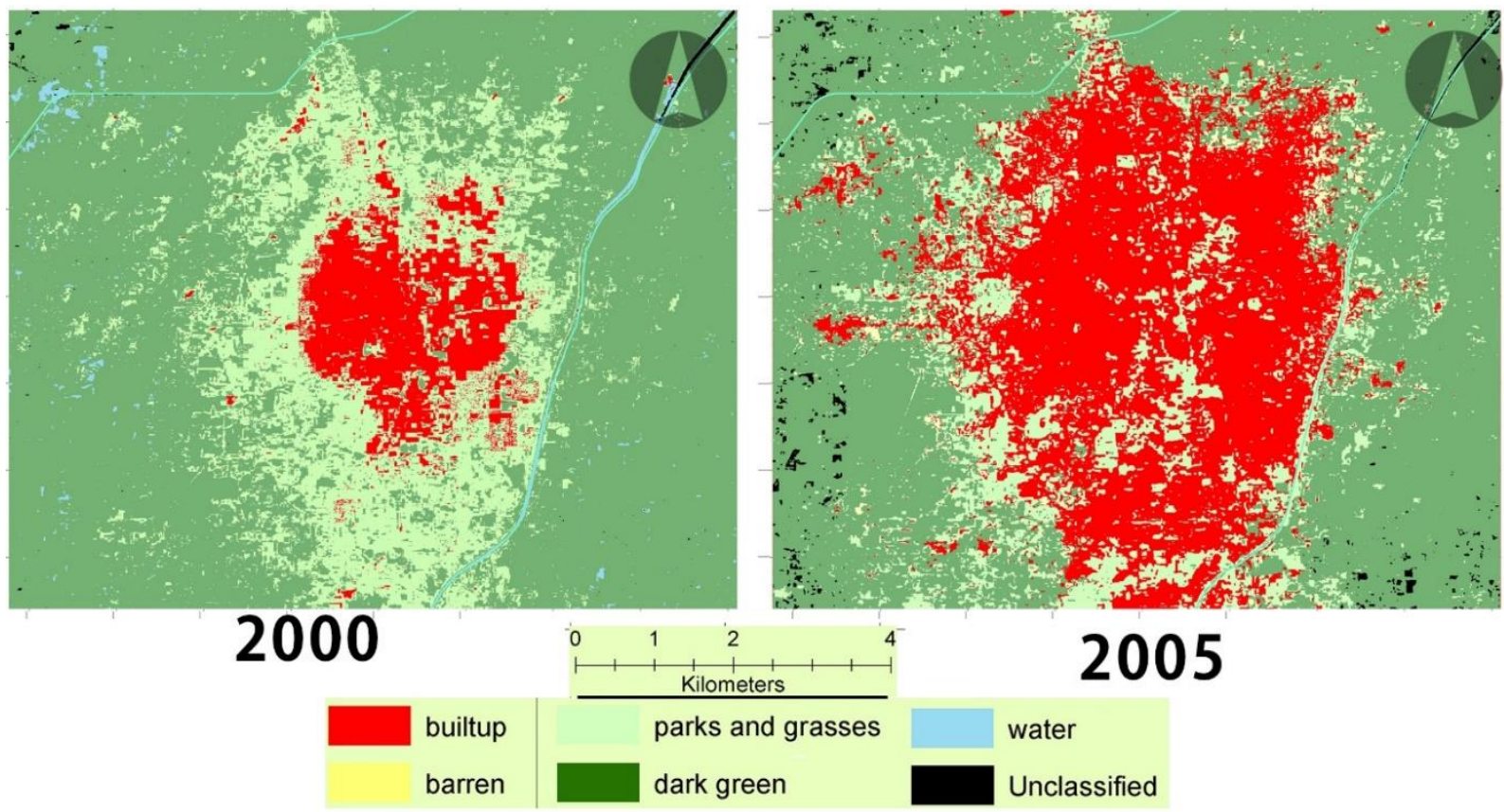

Fig. 5. Map of Land-use of study area of year 2000 and 2005.

Tab. 2. Statistics of Land-use of Study area of year 2000 and 2005.

\begin{tabular}{|c|c|c|c|}
\hline Class & $\mathbf{2 0 0 5 - 2 0 0 0}(\mathbf{h a})$ & Change in percent (\%) & change per year(ha) \\
\hline barren & -1429 & -5 & -285 \\
\hline built-up & 5626 & 20 & 1125 \\
\hline parks and grasses & -2104 & -8 & -420 \\
\hline vegetation cover & -2283 & -9 & -456 \\
\hline
\end{tabular}

In the above table comparison of 2000 to 2005 as shown, from 2000-2005 barren land reduced to -1429 ha with change in percentage $-5 \%$ and rate of change in area per year -285 ha. In case of builtup area increased 5626 ha from 2000-2005 accompany change in percentage $20 \%$ and change in area per year also increased to1125 ha. Parks and grasses decreased to-2104 ha from 2000 to 2005 with change in percentage $-8 \%$ and change in area per year -420 ha observed. Vegetation cover was remarkable decreased -2283 ha keeping change in percentage $-9 \%$ and change in area per year also decreased to -456 ha. 
A. Aziz et al.

\section{Comparison of 2010 to 2015}
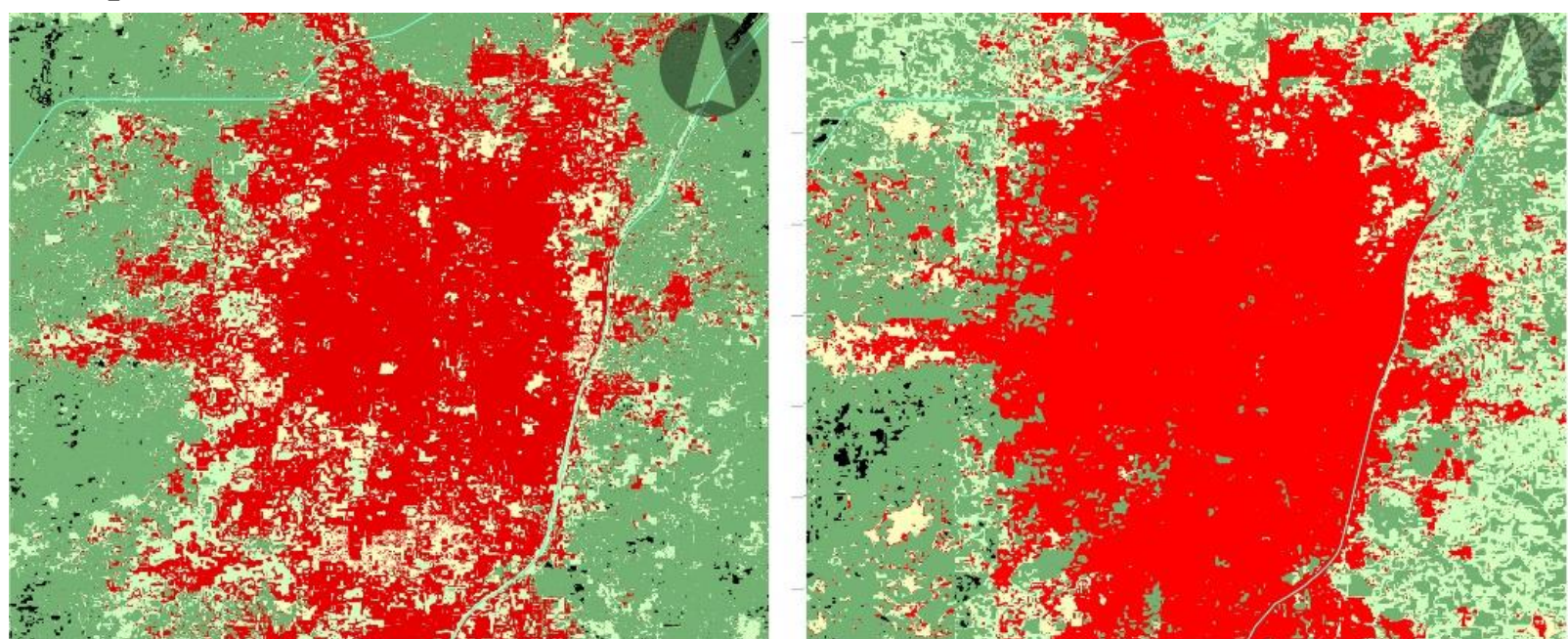

2010
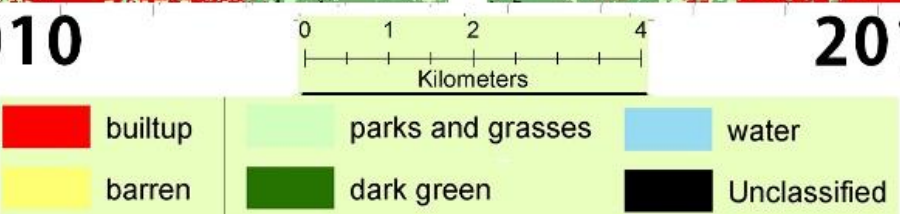

Fig. 6. Map of Land-use of study area of year 2010 and 2015

Tab. 3. Statistics of Land-use of Study area of year 2010 and 2015.

\begin{tabular}{|c|c|c|c|}
\hline Class & $\mathbf{2 0 1 5 - 2 0 1 0}$ & Change in percent & change per year \\
\hline Barren & -26 & -0.1 & -5 \\
\hline Built up & 2784 & 10 & 556 \\
\hline Parks and grasses & 782 & 3 & 156 \\
\hline Vegetation cover & -3852 & -14 & -770 \\
\hline
\end{tabular}

The above table shows the change in tabular form, from 2010 to 2015 where barren land decrease by -26 (ha), built up area due to increase by 2784(ha). Parks and grasses increased due to increase of population by ratio 782 (ha) and vegetation cover decrease by the -3852 (ha).

\section{Comparison from 2000 to 2015: (Total change)}

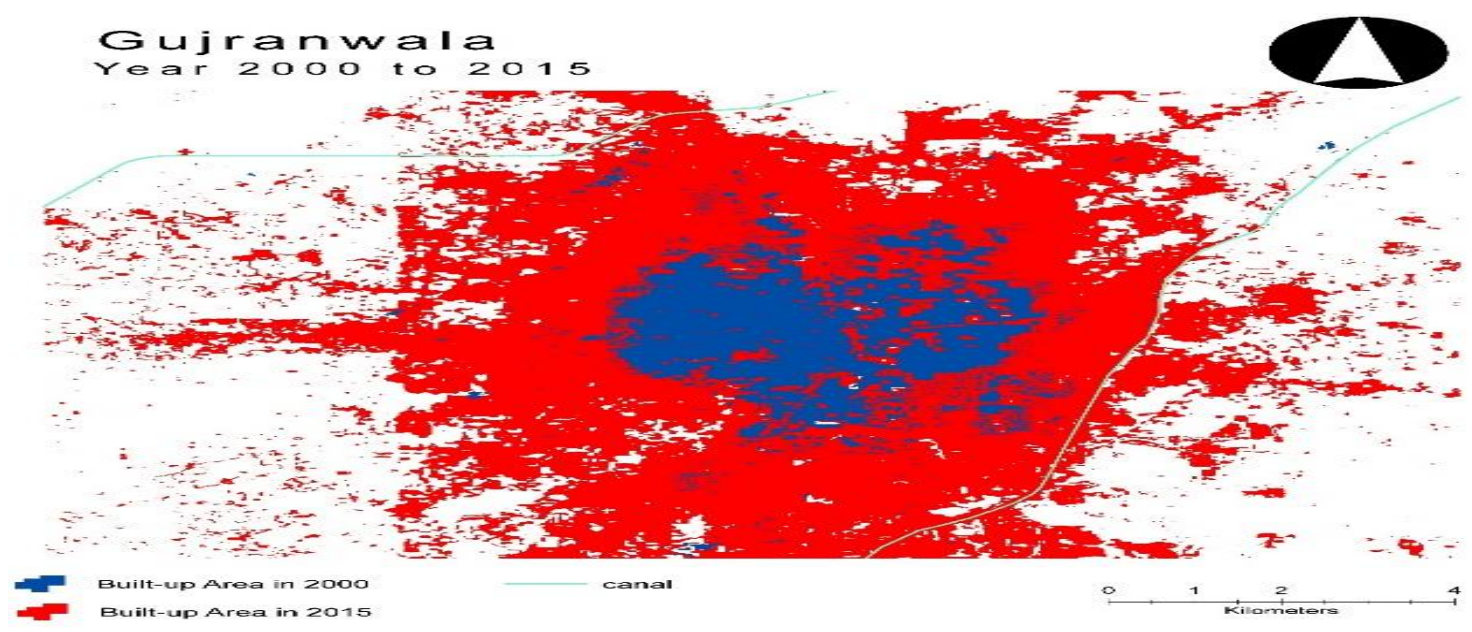

Fig. 7. The map showing difference in 2000 and 2015 land-use of Gujranwala. 
The above table shows the total change from 2000 to 2015 in barren land change occurred by332 (ha). Built up area remarkable changed by 10557 (ha). Parks and grasses become finished by -1854 (ha). Vegetation decreased by -8832 (ha).

The importance of land usage detection is important aspect of policy making and administration for local authorizes at global level. But the rate and magnitude of this fact is not quantified even at global scales. (Seto et al. 2011). The following map shows the overall change in land change from 2000 to 2015 .

Tab. 4. Statistics of Land-use of Study area of year 2000 and 2015.

\begin{tabular}{|c|c|c|c|}
\hline Class & $\mathbf{2 0 1 5 - 2 0 0 0}$ & Change in percent & change per year \\
\hline Barren & -332 & -1.2 & -22 \\
\hline Built up & 10557 & 38.6 & 703 \\
\hline Parks and grasses & -1854 & 12 & -123 \\
\hline Vegetation cover & -8832 & -33 & -588 \\
\hline
\end{tabular}

\section{Prediction of Urban land usage/Expansion}

Earth land surface is the basic source for the performance of human activities (Seto et al. 2011). According to journal trend in the world the urbanization has been increasing day to day due to which the land mostly around the main city is covered by different human activities for different purpose. As the population increased the land is used to construction of buildings road networking, markets and public places, all these phenomena's add the value in land using parameter. shows the expected increase of land usage in urban city based upon the data gathered by remote sensing for multi temporal analysis from 2000 to 2015. Based upon these values the map shows the trend of land usage in future. By using remote sense data, the classification of images was done to detect the change in urban expansion. In low income and low GDP countries the land usage is done without any land usage policy. Land usage and urbanization is highly dominated by the different anthropogenic activities, causes the loss of natural habitat, change of local biodiversity and species extinction. (Seto et al. 2011). The expansion of urban is done without any sequence without any scale as shown in map.

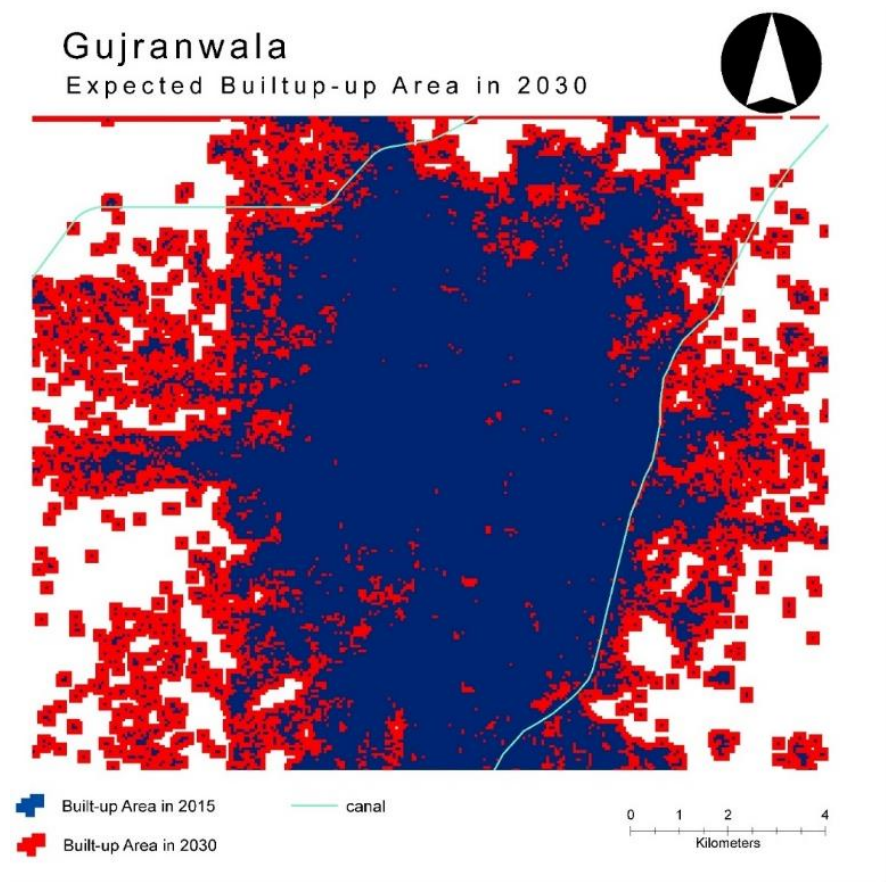

Fig. 6. Prediction map of urban area expansion till 2030. 


\section{Discussion}

Gujranwala the urban and industrialized city of Pakistan is expended geographically, so more and more land is covered by the human structural pattern. In this research the total area of urban city is detected by land man usage for different purpose. The land usage is the basic right of every one being the part of the earth. From the past few years the population is on increasing trend. The land usage monitoring in this paper is not only helpful for the better settlement but also for assessing the change in land surface.

Land use and land cover change is global issue and interrelated to each other with the increase of population also, particularly in urban cities or areas near to urban cities now a day and Pakistan is also facing this problem with changing temporal swift. This issue is enhanced by rapidly increase in growth rate which accelerate the rate of population expansion from outward the city core, due to which the land near to city is used for different purposes to meet the human needs. Land is used when people migrate for better life style, built new houses due to which urban infrastructure expend towards outside the city. As the land is cover by different activities by man, reducing the parks, grasses, agricultural land and natural environment surround, affect the vegetation cover and barren land onto cemented structure by city growth. With the loss of vegetation cover, grasses, agricultural land and natural land, it also reduces the yield of crops, effects the socio-economic status. The environmental issue due to population destroy the natural environment and animal species migrate/ extinct due to harsh environment.

If this issue increased day to day, as the result of un-sequenced expansion then it creates a problem in future. This issue required attention of local government, urban management units and other management authorities to save the nature for batter quality of life in future.

In last 20 years the Earth observation data is used for the detection of land use and land cover change by rapid increased of population so the land is used by biotic and a-biotic component of the environment and this trend is at large scale in tropics, it is a scientific changeling for future outcomes to establish a relation between land use and land cover in a sequences with temporal variations and develop a more comprehensive monitoring systems for urban land use management.

From the start of 21 centuries the Earth observation data by using of modern technology like GIS, remote sensing satellite imaginary is used for the indication of land use and land cover change by rapid increased of population and used as a tool for batter management and also help out in decision making. The land is used by the basic components of physical environment(biotic and a-biotic) and this trend is at large scale in tropics, it is a changeling for future generation to establish a relation between land use and land cover with respect to temporal variations and develop monitoring systems for urban land use management. The terms land use and land cover are interrelated to each other and it is a tool used to understand the relation between the people and their environment. Whenever human involved, the nature becomes disturb, as the land is used for different purposes by local population so it also affects the local ecosystem of that location like the crops production decreased by the pollution, deforestation when land is required for building construction, waste water when added into rainy water gets mixed with the soil and contaminated into the surface to reached at water table and damaged the underground quality of water. When land is covered by cemented material it's also causes flash flooding which erode the upper surface of the soil. In our study area the business zone is established day to day due to which a number of peoples are attached with this locality for theirs trade, local business, and jobs so the peoples migrated towards this area which causes the expansion of urban area.

Land use and land cover change is global issue and interrelated to each other with the increase of population also, particularly in urban cities or areas near to urban cities now a day and Pakistan is also facing this problem with changing temporal swift. This issue is enhanced by rapidly increase in growth rate which accelerate the rate of population expansion from outward the city core, due to which 
the land near to city is used for different purposes to meet the human needs. Land is used when people migrate for better life style, built new houses due to which urban infrastructure expend towards outside the city. As the land is cover by different activities by man, reducing the parks, grasses, agricultural land and natural environment surround, affect the vegetation cover and barren land onto cemented structure by city growth. With the loss of vegetation cover, grasses, agricultural land and natural land, it also reduces the yield of crops, effects the socio-economic status. The environmental issue due to population destroy the natural environment and animal species migrate/ extinct due to harsh environment. The following figure shows a relation between land cover by land use by the ecology of the people and interrelated phenomena's like urban management and decision making in a chain forms.

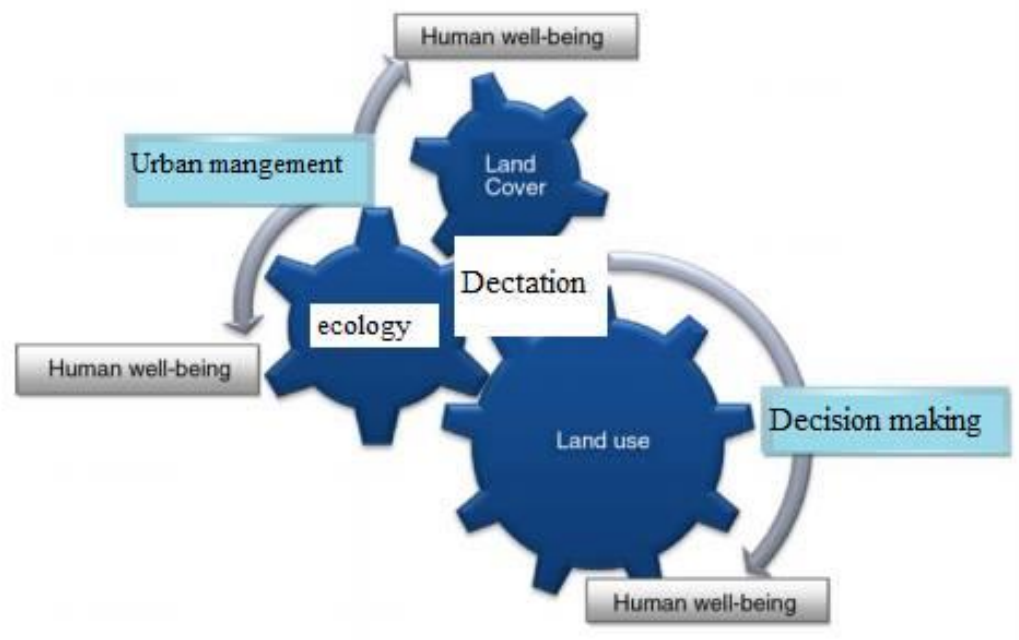

Fig. 8. Impacts of Land-use on ecology.

Fig. 8 shows Relation between land cover and ecology for decision making, Fig. 8. Impacts of Land-use on ecology is made to explain the relationship between the urban ecology and land-use trend. Every person in our research area use the natural land according to his own perspective. Richer a person is, more the land is used. So its detection is very helpful tool for urban management for the well-being of urban society as in case of Gujranwala city. If this issue increased day to day, as the result of expansion then it creates a problem in future. This issue required attention of local government, urban management units and other management authorities to save the nature for batter quality of life in future. From the start of 21 centuries the Earth observation data by using of modern technology like GIS, remote sensing satellite imaginary is used for the indication of land use and land cover change by rapid increased of population and used as a tool for batter management and also help out in decision making. The land is used by the basic components of physical enviroment9 biotic and a-biotic) and this trend is at large scale in tropics, it is a changeling for future generation to establish a relation between land use and land cover with respect to temporal variations and develop monitoring systems for urban land use management. The terms land use and land cover are interrelated to each other and it is a tool used to understand the relation between the people and their environment. Whenever human involved, the nature becomes disturb, as the land is used for different purposes by local population so it also affects the local ecosystem of that location like the crops production decreased by the pollution, deforestation when land is required for building construction, waste water when added into rainy water gets mixed with the soil and contaminated into the surface to reached at water table and damaged the underground quality of water. When land is covered by cemented material it's also causes flash flooding which erode the upper surface of the soil. 
A. Aziz et al.

\section{Conclusion}

The increase of human population required more and more land used for different purposes to meet the everyday needs such as road networking, urban infrastructure, markets, roads and residential colonies, for survival of life. The increase in urban expansion without any planning, creates an ecological problems i.e. ecological pressure, land erosion, deficiency of land for agriculture usage and non-availability of fresh water. Gujranwala city is one of the major city of Pakistan. Currently facing the problems of urban sprawl. This study is conducted to introduce GIS and RS (remote sensing) methods to assist the planners in making better decisions. The change detection technique reveals the directions of urban sprawl and can prepare planners to design the basic infrastructure of the urban area.

According to general trend in the world especially in case of developing countries like Pakistan, the population is increasing day by day due to which more and more land is required for settlement. The problem is not the expansion of urban area but the real problem is the expansion without any sequence or planning. The land for agriculture is deceased due to which annual production is also affected and it decreased the socio-economic status by decreasing the profit.

\section{Recommendations}

In order to resolve the issues related to urban sprawl, urban management department should have introduced a well-planned map for the urban expansion based upon temporal scales and awareness of the people to evaluate the importance of natural landscapes and introduced the methods to use the land in proper and well planned ways.

\section{References}

Statistics, P. B. o. (1999). Population cencus report

Wafa Nori, El Nour Elsiddig, Irmgard Niemeyer (2008) Detection of land cover changes using multi temporal satellite imagery, The International Archives of the Photogrammetry, Remote Sensing and Spatial Information Sciences. Vol. XXXVII. Part B7. Beijing 2008.

Aren C. Seto, Michail Fragkias, Burak Gu " neralp, Michael K. Reilly (2011) A Meta-Analysis of Global Urban Land Expansion, PLoS ONE | www.plosone.org 1 August 2011 | Volume 6 | Issue 8 | e23777.

Carmelo Riccardo Fichera, Giuseppe Modica and Maurizio Pollino (2012) Land Cover classification and change-detection analysis using multi-temporal remote sensed imagery and landscape metrics, European Journal of Remote Sensing - 2012, 45: 1-18 doi: 10.5721/EuJRS20124501.

R.Manonmani, G.Mary Divya Suganya (2010) Remote Sensing and GIS Application in Change Detection Study In Urban Zone Using Multi Temporal Satellite, International Journal of Geomatics and Geosciences, Volume 1, No 1, 2010.

Roy Haines-Young (2009) Land Use Policy (Land use and biodiversity relationships), 02648377/\$ - see front matter (C) 2009 Queen's Printer and Controller of HMSO. Published by Elsevier Ltd. All rights reserved. doi:10.1016/j.landusepol.2009.08.009.

Ali,SA and Tesgaya D (2010) Land use and Land cover change detection between 1985 to 2005 in the part of highland of Eastern Ethiopia using remote sensing and GIS techniques, International Journal of Geo informatics vol, 6, NO 2.June 2010 ISSN 1686-6576 / C- Geo informatics International.

Selçuk Reis (2008) Analyzing Land Use/Land Cover Changes Using Remote Sensing and GIS in Rize, North-East Turkey, Sensors 2008, 8, 6188-6202; DOI: 10.3390/s8106188. ISSN 1424-8220. 
A. Aziz et al.

Ames Bolarinwa Olaleye, Oludayo Emmanuel Abiodun and Queen Igbokwe (2009) Land Use Change Detection and Analysis Using Remotely Sensed Data in Lekki Peninsula Area of Lagos, Nigeria, FIG Working Week 2009 Surveyors Key Role in Accelerated Development Eliat, Isreal, 3-8 May, 2009. 